\title{
The Effect of Energy Drink Consumption on Collegiate Flight Students' Pilot Skills in a Simulated Flight Environment
}

\author{
Chad L. Depperschmidt, Timm J. Bliss, and Conrad L. Woolsey \\ Oklahoma State University
}

\begin{abstract}
Over the last decade, energy drinks have become ubiquitous on college campuses. The global market for these drinks exceeds billions of dollars a year and new 'energy' products are progressively marketed and introduced annually. Outside of college student populations, the effects of energy drinks have been examined extensively. However, among college students, limited energy drink research has been conducted, and this study was the first to examine the effects of energy drinks among collegiate flight students. The purpose of this study was to determine the effects of energy drink consumption on collegiate flight students' pilot skills in simulated flight. Thirty collegiate flight students participated in two distinct simulated flight sessions after consuming a 16-ounce energy drink and a 16-ounce placebo. After students consumed each drink, the researchers evaluated pilot skills in three distinct areas; straight and level flight, complex turns, and in-flight emergencies. Even though statistical analysis on some of the flight session data failed to disprove the null hypothesis $\left(\mathrm{H}_{0}\right)$ : The consumption of energy drinks has no significant effect on collegiate flight students' pilot skills, the results of this investigative study raise new questions and concerns regarding collegiate student pilots and provide a springboard for future research projects.
\end{abstract}

\section{INTRODUCTION}

Since the introduction of Red Bull in the United States in 1997, the energy drink market has grown exponentially. Red Bull sales alone increased from nearly 1 billion cans in 2000, to over 3 billion in 2006 (Red Bull GmbH, 2008). Between 2002 to 2006, the energy drink market increased at an average growth rate of 55\% per year with over 500 new brands of energy drinks being released worldwide in 2006 (Reissig, Strain, \& Griffiths, 2009). During this time frame, energy drink sales increased from just over $\$ 1.0$ billion dollars to estimates of $\$ 3.5$ and $\$ 4.7$ billion in 2006 and 2007 (Cohen, 2008; Reissig et al., 2009). According to a 2010 Ademodhi article, the 5-Hour energy drink, launched in the United States in 2004, has now topped Red Bull to become the most popular energy drink among college students. The popularity of this two ounce shot makes sense because it is incredibly easy to conceal and consume discreetly.

A large part of these increases are due to the addictive properties of energy drinks and aggressive advertising campaigns directed towards college students (Buchanan, 2010; Malinauskas, Aeby, Overton, Carpenter-Aeby \& Barber-Heidal, 2007; \& Pohler, 2010). One example, often seen on college campuses and at athletic events, is energy drink companies giving out free samples of their products. The objective of this strategy is simple; give young people, who have been identified as having a harder time resisting immediate rewards in the face of long term consequences, free samples to get them using a product. Then, once they are hooked, charge high prices and take full advantage of the stimulating, euphoric, and addictive properties of these drinks.

Research indicates that adolescents and young adults (those under age 25) are more vulnerable to substance use, due to incomplete development of the memory, stress, and pleasure reward centers of the brain (Lubman, Yücel \& Hall, 2007; Miller \& Carroll, 2006). This is an important consideration for college students because the earlier they start using energy drinks, the greater their chances of suffering from developmental brain changes that increase the likelihood of future psychological problems including addiction, depression, and anxiety. 


\section{Energy Drink Use among College Students}

Energy drink use has become widespread among college students and evidence suggests that usage rates could be even higher among special student populations such as medical students and athletes who are under increased cognitive and performance demands (Oteri, Salvo, Caputi \& Calapai, 2007; Woolsey, 2007). However, to date, only a handful of studies have been conducted to determine energy drink usage rates among college students and most of these studies have also been concerned with the combined-use of alcohol and energy drinks. Malinauskas et al. (2007) surveyed 496 US college students and found that $51 \%$ reported drinking at least one energy drink each month in the past semester. The top reasons cited for using energy drinks were: insufficient sleep, low energy levels, studying, driving for an extended period of time, and to mix with alcohol or to treat a hangover. Weekly jolt and crash episodes were experienced by $29 \%$ of users, with $22 \%$ reporting headaches and $19 \%$ reporting heart palpitations from consuming energy drinks.

In a July 2008 study, Miller examined the relationships between energy drink consumption and risktaking in 795 undergraduate students. Frequent energy drink consumers (six or more days a month), according to the study's findings, were approximately three times as likely than less-frequent energy drink consumers or non-consumers to have smoked cigarettes, abused prescription drugs, or been in a serious physical fight in the year prior to the survey. In the Miller study, energy drink users reported drinking more alcohol, having more alcohol-related problems, and using marijuana about twice as often as non-consumers. Energy drink users were also more likely to engage in other forms of risk-taking, including unsafe sex, not using a seatbelt, participating in an extreme sport, or doing something dangerous on a dare.

\section{Energy Drink Performance Enhancement Studies}

Research studies have been conducted on the main ingredients found in energy drinks and these studies support energy drink manufacturers claims of increased performance, endurance, concentration, reaction time, and enhanced mood (Seidl, Peyrl, Nicham \& Hauser, 2000; Warburton, Bersellini \& Sweeney, 2001; Scholey \& Kennedy, 2004a; 2004b; Deixelberger-Fritz). Studies that examined the traditional ingredients in energy drinks have found sustained attention and reaction time (DeixelbergerFritz et al., 2003; Alford, Cox \& Wescott, 2001; Warburton et al., 2001), improved mood and mental performance (Smit \& Rogers, 2002; Deixelberger-Fritz et al., 2003), and improved driving performance and alertness (Alford et al., 2001; Warburton et al., 2001; Reyner \& Horne, 2001; 2002). Researchers note a synergistic affect when the individual ingredients within energy drinks are mixed together and improvements beyond what caffeine alone will provide (Deixelberger-Fritz et al., 2003; Scholey \& Kennedy, 2004a, 2004b).

\section{Ingredients in Energy Drinks}

In the basic energy drink, the stimulant and euphoric effects are felt from the main ingredients of caffeine, glucuronolactone (i.e., glucose), taurine, B-complex vitamins, inositol, panthenol, and niacin (Oteri et al., 2007). What college students may be unaware of is that newer brands of energy drinks such as Spike and Redline, contain up to 4 times the amount of caffeine per ounce, and also contain powerful herbal compounds such as yohimbine hydrochloride (HCL) and evodamine which are far more dangerous stimulants than caffeine (Energyfiend.com, 2010). Because of previous serious health complications experienced by users, these drinks now contain warning labels recommending not consuming more than 4 ounces of these 8 ounce drinks at one time. However, these are still sold commonly at convenience stores. 


\section{Energy Drink and Pilot Studies}

At the time of this study, only one additional study (Deixelberger-Fritz et al., 2003) researched the effects of energy drinks on pilots. The Deixelberger-Fritz et al. study concluded that energy drink participants experienced an improvement or increase in decision time and performance increments. While this study evaluated licensed pilot participants using cognitive performance tests and psychophysiological state tests, it did not evaluate participants in realistic flight scenarios that would examine pilot skill. Furthermore, the study consisted of twenty-four commercial and military pilots with age ranges from 23-40 years of age; not collegiate flight students.

\section{RESEARCH METHODOLOGY}

Today millions of people, including college students, are turning to energy drinks to help them get through the day and to improve alertness. As witnessed by widespread use and positive testimonials, energy drinks appear to be perceived as safe and a socially acceptable way to increase energy and enhance performance.

The main question is: do energy drinks really enhance performance on the execution of complex skills? Additionally, what happens when an individual is put under a naturally stressful situation? Does energy drink consumption actually have a positive effect on collegiate flight students' skill set (i.e., increasing their abilities to accurately conduct instructed flight procedures; responding to flight instructions and procedures; and completing instructed flight procedures in a prescribed amount of time)? The purpose of this research study was to answer these questions. The following hypothesis was established for this research study:

$\mathrm{H}_{0}$ : The consumption of energy drinks has no significant effect on collegiate flight students' pilot skills.

$\mathrm{H}_{1}$ : The consumption of energy drinks has a significant effect on collegiate flight students' pilot skills.

To measure any possible effects from energy drink consumption on student pilot skill, this study used a two-group (Group A and B) reverse treatment pretest-posttest design. Thirty collegiate student pilots participated in two distinct flight sessions in a Fidelity Flight Simulation MOTUS 622i, which can be configured for multiple aircraft types and training scenarios. Each student pilot participated in two flight sessions, completed on separate days to eliminate any potential residual effects from the energy drink on each participant. All sixty flight sessions were completed within a two week timeframe in March and April of 2010. Participants conducted each flight session after consuming either a 16-ounce energy drink or a comparable tasting 16-ounce placebo without caffeine. All participants were randomly assigned to both Group A or Group B. Group A participants received the energy drink for flight session one and the placebo for flight session two. Group B participants received the reverse; placebo for flight session one and the energy drink for flight session two.

Both flight sessions created by the researchers contained segments of straight and level flight, complex turns, and an in-flight emergency. Each student began their simulated flight with a straight and level attitude, and they were then verbally instructed by the simulator technician to complete the tasks of the flight scenario. Weather conditions for each flight session consisted of daytime VFR conditions, calm winds, clear skies, and unlimited visibility. Each flight session was identical in complexion and duration, with the exception of the in-flight emergencies. In each session, straight and level flight was measured for the same number of segments and duration, and complex turns contained the same combinations of change in altitude, heading, and airspeed. Each flight session was different in the order of instructed tasks and each session began at a different heading and altitude. These changes in each flight session limited 
each participant's ability to improve their performance due to experience in the flight simulator, while enabling researchers the ability to directly compare results of both flight sessions. The two in-flight emergencies, an engine failure and an engine fire, required the flight students to review and act based on a checklist placed in the simulator before the start of their flight session. The student had to locate the proper in-flight emergency checklist and follow the required five steps of the checklist.

For each flight session, the flight student consumed a16-ounce energy drink or placebo in a nonidentifying white cup with a lid and a straw. This prevented the participant from identifying the color of the drink and potentially recognizing the drink's brand. The student was given five minutes to consume their 16-ounce drink; and after consuming the drink, the student waited an additional thirty minutes before beginning their flight scenario in order for the energy drink to be absorbed in the participant's body.

There were three popular energy drink brands used in this study: Monster, Rockstar, and NOS. In 2008, these drink brands represented three of the six most popular energy drinks in the United States. As a group, Monster, Rockstar, and NOS represented approximately $40 \%$ of 2008 US sales (The Top 15 Energy Drink Brands, 2008). Each of the three energy drinks used in this study were randomly assigned to each participant, with an even distribution of each product administered ten times. The researchers developed a placebo similar in taste to the energy drinks used in this study; however, only ingredients that did not contain caffeine or other stimulants were used to create the placebo.

Each participant's two flight sessions were recorded using video and audio recording devices. A video recorder was used to record progression of time and cockpit flight instrumentation for the duration of each flight session. Additionally, a microphone was attached to the participant's headset to record audio communication between the participant and simulator technician. For each flight scenario, the video recorder was fixated on a computer monitor that projected the flight instruments of the flight simulator. Additionally, a timer with measurements to a tenth of a second was placed next to the computer monitor with the flight instruments. Both the monitor and timer were included in each video recording. The microphone was connected from the participant's headset to the video recorder. This recorded all audio communication, real time, from the participant onto the video recording. Before each flight session was started, the simulator technician would initiate the microphone, video recorder, and timer allowing the researchers to evaluate the flight session for accuracy through video, audio, and time.

To test statistical significance of the means from the data collected from the flight sessions, a dependent paired sample $t$ test was conducted at the .05 significance level (confidence interval of 95\%). A confidence interval of $95 \%$ means that in case of rejecting the $\mathrm{H}_{0}$, the researchers are $95 \%$ or more certain they did the right thing. For statistical analysis, data was entered into Statistical Package for the Social Sciences (SPSS) software. The calculations from SPSS included Mean, N = sample size, SD = standard deviation, $t=\mathrm{t}$ statistic, $\mathrm{DF}=$ degrees of freedom, and Sig. = significance level.

\section{Selection of the Research Population}

The participating collegiate flight students were undergraduate aviation students majoring in Professional Pilot at Oklahoma State University. In order to meet the requirements for this study, each flight student had to be currently enrolled in a flight course for academic credit, had logged a minimum of 25 total flight hours, and be at least 18 years of age. A total of 41 flight students volunteered to participate in this study; however, only 30 students actually completed the required two flight sessions. Permission to perform this research study involving OSU flight students was approved by the Institutional Review Board at Oklahoma State University, Stillwater, Oklahoma, on March 2, 2010 (IRB application number: ED1017). 
A brief demographic survey was administered to each participant before they began their first flight session. One of the questions asked the participating flight student to identify their academic classification. Table 1 indicates that of the 30 participants; $7 \%$ were freshman, $20 \%$ were sophomores, $40 \%$ were juniors, and $33 \%$ of participants were seniors.

\section{Table 1: Academic Classification of Participants}

\begin{tabular}{lc|c}
$\begin{array}{c}\text { Academic } \\
\text { Classification }\end{array}$ & $\begin{array}{c}\text { Number of } \\
\text { Participants }\end{array}$ & $\begin{array}{c}\text { Percentage of } \\
\text { Participants }\end{array}$ \\
\hline \hline Freshman & 2 & $7 \%$ \\
Sophomore & 6 & $20 \%$ \\
Junior & 12 & $40 \%$ \\
Senior & 10 & $33 \%$
\end{tabular}

The total number of logged flight hours was also solicited from the participating flight students. As shown in Table 2, 53\% of participants had 149 or fewer logged flight hours; whereas, $47 \%$ of participants had 150 or more logged flight hours.

Table 2: Logged Flight Hours of Participants

\begin{tabular}{lc|c}
$\begin{array}{c}\text { Number of Logged } \\
\text { Flight Hours }\end{array}$ & $\begin{array}{c}\text { Number of } \\
\text { Participants }\end{array}$ & $\begin{array}{c}\text { Percentage of } \\
\text { Participants }\end{array}$ \\
\hline \hline & & \\
$25-49$ & 2 & $7 \%$ \\
$50-99$ & 7 & $23 \%$ \\
$100-149$ & 7 & $23 \%$ \\
$150-199$ & 5 & $17 \%$ \\
$200-249$ & 1 & $3 \%$ \\
250 \& Over & 8 & $27 \%$
\end{tabular}

\section{RESULTS}

This study evaluated the pilot skill of collegiate flight students in three distinct areas; straight and level flight, complex turns, and in-flight emergencies. After the thirty participants completed both of their simulated flight sessions, the researchers were able to statistically compare each participant's flight results after consuming the energy drink and the placebo.

\section{Straight and Level Flight}

Each simulated flight session consisted of four different segments of straight and level flight. Each of these segments lasted thirty seconds. Each participating flight student began their flight session in a straight and level attitude and was verbally instructed by the simulator technician to proceed with their flight holding a specific altitude, heading, and airspeed. Measurements were recorded by the researchers to evaluate the student's ability to hold this straight and level flight in three specific parameters; altitude, 
heading, and airspeed. To measure each participant's flight results, researchers viewed the video recording of the participant's flight instruments. The video was paused every three seconds to allow the researcher to accurately record the current position of flight instruments indicating altitude, heading, and airspeed. Each of the three parameters was recorded in specific increments; altitude was recorded in increments of 100 feet, airspeed was recorded in increments of five knots, and heading was recorded in increments of five degrees.

Regarding each segment of straight and level flight, the participant was verbally instructed by the simulator technician in each of the three parameters. For example;

- $\quad$ Proceed straight and level at $180^{\circ}, 95$ Knots, and 2,500 feet.

Overall accuracy of each straight and level segment completed by the participant was measured by assigning a point system based on his/her ability to hold the instructed parameters of straight and level flight. For each increment of inaccuracy, the participant was assigned one point. All points were then calculated and recorded. Table 3 represents a nine-second example of a participant's straight and level flight segment. Zero (0) seconds represent the starting point of each straight and level segment: 1600 feet, 95 knots, and 150 degrees heading. The shaded boxes indicate the participant's instruments at that particular time $(0,3,6$, or 9 seconds) in the straight and level segment. For example, at the six second interval, the participant was flying at 1,700 feet instead of the required 1,600 feet and 90 knots instead of the required 95 knots; resulting in a two-point penalty.

Table 3: Measuring Straight and Level Flight Accuracy

\begin{tabular}{|c|c|c|c|c|c|c|}
\hline \multicolumn{7}{|c|}{ Altitude - 0 Seconds } \\
\hline 1300 & 1400 & 1500 & 1600 & 1700 & 1800 & 1900 \\
\hline \multicolumn{7}{|c|}{ Heading - o Seconds } \\
\hline 135 & 140 & 145 & 150 & 155 & 160 & 165 \\
\hline \multicolumn{7}{|c|}{ Airspeed - 0 Seconds } \\
\hline 80 & 85 & 90 & 95 & 100 & 105 & 110 \\
\hline
\end{tabular}

\begin{tabular}{|l|c|c|c|c|c|c|}
\hline \multicolumn{7}{|c|}{ Altitude - 3 Seconds } \\
\hline 1300 & 1400 & 1500 & $\mathbf{1 6 0 0}$ & 1700 & 1800 & 1900 \\
\hline \multicolumn{7}{|c|}{ Heading - 3 Seconds } \\
\hline \multicolumn{7}{|c|}{ Airspeed - 3 Seconds } \\
\hline 135 & 140 & 145 & $\mathbf{1 5 0}$ & 155 & 160 & 165 \\
\hline \multicolumn{7}{|c|}{} \\
\hline 80 & 85 & 90 & 95 & 100 & 105 & 110 \\
\hline
\end{tabular}

*Zero point deduction, all pre-set parameters met. 


\begin{tabular}{|l|c|c|c|c|c|c|}
\hline \multicolumn{7}{|c|}{ Altitude - 6 Seconds } \\
\hline 1300 & 1400 & 1500 & $\mathbf{1 6 0 0}$ & 1700 & 1800 & 1900 \\
\hline \multicolumn{7}{|c|}{ Heading - 6 Seconds } \\
\hline \multicolumn{7}{|c|}{ Airspeed - 6 Seconds } \\
\hline 135 & 140 & 145 & $\mathbf{1 5 0}$ & 155 & 160 & 165 \\
\hline \multicolumn{7}{|c|}{9} \\
\hline 80 & 85 & 90 & 95 & 100 & 105 & 110 \\
\hline
\end{tabular}

*Two point deduction (1 point for $100 \mathrm{ft}$ increase in altitude and 1 point for 5 knots decrease in airspeed).

\begin{tabular}{|c|c|c|c|c|c|c|}
\hline \multicolumn{7}{|c|}{ Altitude - 9 Seconds } \\
\hline 1300 & 1400 & 1500 & 1600 & 1700 & 1800 & 1900 \\
\hline \multicolumn{7}{|c|}{ Heading - 9 Seconds } \\
\hline 135 & 140 & 145 & 150 & 155 & 160 & 165 \\
\hline \multicolumn{7}{|c|}{ Airspeed - 9 Seconds } \\
\hline 80 & 85 & 90 & 95 & 100 & 105 & 110 \\
\hline
\end{tabular}

*Four point deduction ( 1 point for $100 \mathrm{ft}$ increase in altitude, 1 point for 5 degrees off in heading, and 2 points for 10 knots decrease in airspeed).

When comparing participants' straight and level segments after consuming both energy drink and placebo, the majority of participants completed their straight and level segment more accurately after consuming the placebo. As shown in Table 4, 87\% of participants had a larger number of point deductions after consuming the energy drink.

Table 4: Participants Receiving Deductions - Straight and Level Flight Session

\begin{tabular}{lc|c} 
& $\begin{array}{c}\text { Total } \\
\text { Participants }\end{array}$ & Percentage \\
\hline \hline & 26 & \\
Number of Participants Receiving Deductions - Energy Drink & 4 & $87 \%$ \\
Number of Participants Receiving Deductions - Placebo & $13 \%$
\end{tabular}

Furthermore, after comparing the total number of points for all thirty participants, the energy drink sessions had more total point deductions than the placebo sessions. Table 5 indicates the energy drink sessions had a total of 1600 point deductions; whereas, the placebo sessions only had a total of 947 point deductions. 
Table 5: Participant's Total Point Deduction - Straight and Level Flight Session

\begin{tabular}{lc|c|c|c|c|c|c|c|} 
& $\begin{array}{c}\text { Total } \\
\text { Points }\end{array}$ & Percentage & $\mathrm{N}$ & $\mathrm{M}$ & $\mathrm{SD}$ & $t$ & $\mathrm{DF}$ & Sig. \\
\hline \hline $\begin{array}{l}\text { Total Point Deductions after } \\
\text { Energy Drink Consumption }\end{array}$ & 1600 & $63 \%$ & 30 & 53.33 & 27.42 & & & \\
$\begin{array}{l}\text { Total Point Deductions after } \\
\text { Placebo Consumption }\end{array}$ & 947 & $37 \%$ & 30 & 31.57 & 22.59 & & & \\
\end{tabular}

\section{Complex Turns}

Each flight session also consisted of three complex turns including a change in altitude, heading, and airspeed. For each complex turn, participants were instructed to simultaneously change their altitude and heading while holding a required airspeed instructed by the technician. The measurement of each complex turn consisted of timing the participants from beginning to completion of the instructed complex turn. Each complex turn in each flight session was different in the amount of change in altitude, heading, and airspeed. For example, the participant was verbally instructed by the simulator technician to change altitude, heading, and airspeed:

- Decrease and hold airspeed to 70 knots, climb to 2,800 feet, and change course to $240^{\circ}$.

Since both flight sessions were started at different headings and altitudes, the complex turns were not the same to the participant; however, the complex turns were identical from a measurement standpoint for the researchers. As shown in Table 6, when measuring the total amount of time to complete the complex turns, 16 of the 30 participants (53\%) completed the maneuver in less time after consuming the energy drink. In comparison, 14 of the students (47\%) completed the maneuver in less time after consuming the placebo.

Table 6. Participant's Time to Complete Complex Turn

\begin{tabular}{|c|c|c|c|c|c|c|c|}
\hline & Participants & $\begin{array}{c}\text { Total } \\
\text { Seconds } \\
\end{array}$ & $\begin{array}{c}\text { Average } \\
\text { Time per } \\
\text { Participant }\end{array}$ & $\mathrm{SD}$ & $t$ & $\mathrm{DF}$ & Sig. \\
\hline Quicker Completion - Energy Drink & 16 & 1272 & $79.5 \mathrm{Sec}$. & 6.15 & 7.33 & 14 & 0.00 \\
\hline Quicker Completion - Placebo & 14 & 1390 & $99.2 \mathrm{Sec}$. & 9.08 & & & \\
\hline
\end{tabular}

But as a follow-up, after each complex turn the participants were instructed to complete a straight and level flight segment. The instructed ending point of the complex turn was the same altitude, heading, and airspeed parameters as the upcoming straight and level flight segment. The measurement of the straight and level flight segments after each complex turn did not begin until participants were able to achieve altitude, heading, and airspeed simultaneously for one second. Participants were measured to see how long it would take them to level out and begin their straight and level flight segment. 
In Table 7, all 30 participants are compared to their response times to begin the straight and level flight segments after completing their complex turns in both flight sessions (energy drink and placebo).

Table 7. Participant Response Time to Achieve Straight and Level Flight

\begin{tabular}{lc|c|c|c|c|c} 
& $\mathrm{N}$ & Average Seconds & SD & $t$ & DF & Sig. \\
\hline \hline Participants Consuming Energy Drink & 30 & 88.73 & 42.43 & -.834 & 29 & .411 \\
Participants Consuming Placebo & 30 & 79.96 & 43.85 & & &
\end{tabular}

As shown in Table 7, the energy drink participants, on average, took approximately 10 additional seconds to achieve straight and level flight than the placebo participants. So even though the participant may have completed the complex turn quicker after consuming the energy drink, it took that participant longer to get the aircraft in the proper attitude to begin the straight and level flight segment.

\section{In-Flight Emergencies}

Each flight session consisted of an in-flight emergency that required participants to identify the proper checklist and react based on the instructions of the proper checklist. Since each emergency was different, researchers compared the in-flight emergency within each flight session separately.

Upon being verbally informed of an in-flight emergency by the simulator technician, the participant was expected to review and follow a five-step checklist that was placed in the flight simulator before the beginning of the flight session. Depending on the flight session, each participant experienced an engine failure or engine fire. The checklist required participants to act as follows:

\section{Engine Failure}

- Airspeed - 60 KIAS

- Mixture - Idle Cut Off

- Ignition Switch - Off

- Wing Flaps $-30^{\circ}$ Required

- Master Switch - Off

Engine Fire

- Mixture - Idle Cut Off

- Fuel Selector Valve - Off

- Master Switch - Off

- Alternate Air - Off

- Airspeed - $100 \mathrm{KIAS}$

When measuring the ability of participants to accurately follow the five-step checklist in order, participants were less accurate after consuming the energy drink than after consuming the placebo. Table 8 illustrates the number of accurate and complete steps accomplished by participants after consuming the energy drink and the placebo. 
Table 8: Participant's In-Flight Emergency Checklist Accuracy

\begin{tabular}{l|c|c}
\multicolumn{3}{c}{ Energy Drink } \\
Steps Complete & Participants & Percentage \\
\hline \hline & & \\
Zero & 1 & $3 \%$ \\
One & 0 & $0 \%$ \\
Two & 2 & $7 \%$ \\
Three & 0 & $0 \%$ \\
Four & 3 & $10 \%$ \\
Five & 24 & $80 \%$
\end{tabular}

\begin{tabular}{c|c|c}
\multicolumn{2}{|c}{ Placebo } \\
Steps Complete & Participants & Percentage \\
\hline \hline & & \\
Zero & 0 & $0 \%$ \\
One & 0 & $0 \%$ \\
Two & 1 & $3 \%$ \\
Three & 0 & $0 \%$ \\
Four & 4 & $14 \%$ \\
Five & 25 & $83 \%$
\end{tabular}

Table 9 compares the total number of accurate and completed in-flight emergency checklist steps completed by participants after consuming the energy drink and the placebo.

Table 9: Participant's Number of Accurate Completed Checklist Steps

\begin{tabular}{lc|c|c|c|c|c|c|} 
& $\mathrm{N}$ & $\begin{array}{c}\text { Total } \\
\text { Accurate } \\
\text { Steps }\end{array}$ & $\begin{array}{c}\text { Average } \\
\text { Steps }\end{array}$ & SD & $t$ & DF & Sig. \\
\hline \hline Energy Drink & 30 & 136 & 4.53 & 1.16 & & & \\
Placebo & 30 & 143 & 4.76 & .626 & .909 & 29 & .371
\end{tabular}


Table 10. Participant's Time to Complete In-Flight Emergency Checklist

\begin{tabular}{|c|c|c|c|c|c|c|c|}
\hline & $\mathrm{N}$ & $\begin{array}{c}\text { Total } \\
\text { Seconds } \\
\end{array}$ & $\begin{array}{l}\text { Average } \\
\text { Seconds }\end{array}$ & $\mathrm{SD}$ & $t$ & DF & Sig. \\
\hline Energy Drink & 30 & 1565 & 52.16 & 23.73 & -1.16 & 29 & 253 \\
\hline Placebo & 30 & 1397 & 46.56 & 15.86 & & & \\
\hline
\end{tabular}

In Table 10, the total amount of time to complete the in-flight emergency checklist is compared between participants after consuming the placebo and energy drinks.

\section{CONCLUSIONS}

Several studies have reported performance enhancing effects of energy drinks, which contributed to their increased usage for performance situations (Ballard, Wellborn-Kim \& Clauson, 2010; Smit, H. J., Cotton, J. R., Hughes, S. C. \& Rogers, P. J., 2004; and Smit \& Rogers, 2002). The 5-Hour energy drink television commercials with father and son NASCAR drivers Rusty and Steve Wallace are an example of this performance enhancement marketing strategy (5-Hour Energy, 2010). Maintaining this focus on performance-based considerations, the researchers studied the overall effects of energy drink consumption on pilot skills in collegiate flight students in three distinct areas; straight and level flight, complex turns, and in-flight emergencies.

\section{Straight and Level Flight Discussion}

When comparing the participating student pilots' straight and level flight segments, $87 \%$ of the pilots had a larger number of point deductions after consuming the energy drink. Moreover, after comparing the total number of points for all 30 pilots, the energy drink sessions had a total of 1,600 point deductions; whereas, the placebo sessions only had a total of 947 point deductions. After analyzing total point deductions, a paired sample $t$ test $(\mathrm{t}(30)=-5.721$, Sig. $=0.00)$ resulted in statistical significance probability that the relationship between the two variables exists and is not due to chance. Therefore, the null hypothesis, $H_{0}$ : The consumption of energy drinks has no significant effect on collegiate flight students' pilot skills, is rejected at the .05 significance level.

\section{Complex Turns Discussion}

When measuring the total amount of time to complete the complex turns, 53\% of the student pilots completed the maneuver quicker after consuming the energy drink. While some may view this as a performance-based improvement, it actually took the energy drink participants approximately 10 additional seconds to recover from the complex turn and achieve straight and level flight when compared to the placebo participants. For statistical analysis, a paired sample $t$ test was performed on complex turn completion and the response time to achieve straight and level flight. Results of the test $(\mathrm{t}(30)=7.338$, Sig. $=0.00)$ indicated statistical significance for time to complete complex turns; however recover time to achieve straight and level flight after completing the complex turn was not statistically significant $(\mathrm{t}(30)=$ -.834 , Sig. $=.411)$ at the .05 significance level. Even though it took the energy drink participants longer to recover from the complex turn, the analyzed results of recovery time to achieve straight and level flight 
after completing the complex turn was not statistically significant and the null hypothesis, $H_{0}$ : The consumption of energy drinks has no significant effect on collegiate flight students' pilot skills, was not rejected for this segment of the flight session.

\section{In-flight Emergency Checklist Discussion}

When measuring the ability of the student pilots to accurately follow (in order) the five-step in-flight emergency checklist, participants were less accurate after consuming the energy drink compared to the placebo. On average, the energy drink pilots accurately completed 4.5 steps of the five-step checklist; whereas, the placebo pilots accurately completed 4.8 steps. Furthermore, it took the energy drink participants an average of 52 seconds to complete the in-flight emergency checklist; whereas the placebo participants were able to complete the checklist in lesser time, an average of 47 seconds.

While the descriptive data recorded during the in-flight emergency flight sessions indicated an overall improvement in flight performance for the student pilots after consuming the placebo drink; surprisingly, the completion of emergency steps and the total time to complete the steps were not statistically significant. Results of $\mathrm{t}$ tests performed on number of accurate emergency steps completed $(\mathrm{t}(30)=.909$, Sig. $=.371)$ and total time to complete emergency steps $(\mathrm{t}(30)=-1.167$, Sig. $=.253)$ were not statistically significant at the .05 significance level; therefore; the null hypothesis, $H_{0}$ : The consumption of energy drinks has no significant effect on collegiate flight students' pilot skills, was not rejected for the in-flight emergency segment of the flight session.

\section{FINAL REMARKS}

Perhaps gulping down an energy drink is perceived by some as a quick way to gain extra energy to get through the day, compensate for perceived nutritional deficiencies in herbs, vitamins and minerals to boost endurance, or improve brain function. However, as demonstrated by this study, college flight students became less able to perform routine flight maneuvers or apply what they have learned to unpredicted flight situations; providing an argument that the ingredients of energy drinks reduce performance decrements due to reduced alertness and concentration.

Even though there were limitations to this study: (1) the number of eligible participants during the data collection phase of this project was relatively small; therefore, the generalization of findings may be somewhat limited, (2) this study was conducted in Oklahoma and to students at one university, and (3) homogeneity, all participants were flight students whom followed the same "pilot training" curriculum the results provide important and novel information regarding the effects of energy drink consumption on pilot skills of collegiate flight students. Most important is the finding that the energy drink pilots made more performance errors when compared to the placebo pilots in all three distinct areas of the simulated flight session: straight and level flight, complex turns, and in-flight emergencies; even though no statistical evidence from three of the flight session investigations was found to support this research finding.

Regardless of the lack of statistical significance of the research data, this type of investigation should continue. Further research should be conducted to identify if collegiate flight students recognize the amounts of caffeine and other active ingredients that are present in the wide variety of energy drinks they consume, and the physical side effects associated with energy drink consumption. Furthermore, additional simulated flight studies should be performed to determine effects that energy drink consumption may have on collegiate flight students' performance on skill sets in the cockpit. 


\section{REFERENCES}

5-Hour Energy. (2010). Retrieved May 21, 2010 from http://www.5hourenergy.com/racing/default.asp

Ademodhi, A. (2010). Students weigh cost and benefits of energy drinks during finals. The Transcript. Retrieved May 26, 2010 from http://media.www.owutranscript.com/media/storage/paper1413/news/2010/04/29/News/Students. Weigh.Cost.And.Benefits.Of.Energy.Drinks.During.Finals-3917175.shtml

Alford, C., Cox, H., \& Wescott, R. (2001). The effects of red bull energy drink on human performance and mood. Amino Acids, 21, 139-150.

Ballard, S. L., Wellborn-Kim, J. J., \& Clauson K. A. (2010, April). Effects of commercial energy drink consumption on athletic performance and body composition. The Physician and Sportsmedicine, $38(1), 107-17$.

Buchanan, M. (2010). Addiction to energy drinks. Retrieved August 16, 2010 from http://www.helium.com/items/845026-addiction-to-energy-drinks

Cohen, H. (2008, April 2). Kids + energy drinks = dangerous mix. The Miami Herald. Retrieved December 8, 2009, from http://seattletimes.nwsource.com/html/health/2004322357_zhea02energy.htm

Deixelberger-Fritz, D., Tischler, M.A., \& Wolfgang K. K. (2003). Changes in performance, mood state and workload due to energy drinks in pilots. International Journal of Applied Aviation Studies, 3(2), 195-205.

Energyfiend.com (2010). Caffeine content of drinks. Retrieved August 16, 2010 from http://www.energyfiend.com/the-caffeine-database/

Kapner, D. A. (2004). Ephedra and energy drinks on college campuses. The Higher Education Center for Alcohol and Other Drug Abuse and Violence Prevention. Retrieved December 8, 2009, from http://www.higheredcenter.org/files/product/energy-drinks.pdf.

Lubman, D. I., Yücel, M. \& Hall, W. D. (2007) Substances and the adolescent brain: A toxic combination? Journal of Psychopharmacology, 21, 792-794.

Malinauskas, B. M., Aeby, V. G., Overton, R. F., Carpenter-Aeby, T., \& Barber-Heidal, K. (2007). A survey of energy drink consumption patterns among college students. Nutrition Journal, 6, 35. doi:10.1186/1475-2891-6-35

Miller, K. E. (2008, July 25). Energy drinks linked to risk-taking behaviors among college students. Science Daily. Retrieved May 27, 2010, from http://www.sciencedaily.com-/releases/2008/07/080724150438.htm

Miller, W. R., \& Carroll, K. M. (2006). Rethinking substance abuse: What the science shows, and what we should do about it. New York: Guilford Press. 
Oteri, A., Salvo, F., Caputi, A., \& Calapai, G. (2007). Intake of energy drinks in association with alcoholic beverages in a cohort of students of the school of medicine of the University of Messina. Alcoholism: Clinical and Experimental Research, 31(10), 1677-1681.

Pohler, H. (2010, January). Caffeine intoxication and addiction. The Journal for Nurse Practitioners, 6 (1), 49-52.

Red Bull GmbH - Company History. (2008). Retrieved on November 15, 2008, from http://www.fundinguniverse.com/company-histories/Red-Bull-GmbH-Company-History.html.

Reissig, C.J., Strain, E.C., \& Griffiths, R.R. (2009). Caffeinated energy drinks: A growing problem. Drug and Alcohol Dependence, 99, 1-10. doi:10.1016/j.drugalcdep.2008.08.001

Reyner, L. A., \& Horne, J. A. (2001). Beneficial effects of an "energy drink" given to sleepy drivers. Amino Acids, 20, 83-89.

Reyner, L. A., \& Horne, J. A. (2002). Efficacy of a functional energy drink in counteracting driver sleepiness. Physiology and Behavior, 75, 331-335.

Scholey, A. B., \& Kennedy, D. O. (2004a). Cognitive and physiological effects of an "energy drink": An evaluation of the whole energy drink and of glucose, caffeine and herbal flavoring fractions. Psychopharmacology, 176, 320-330.

Scholey, A. B., \& Kennedy, D. O. (2004b). A glucose-caffeine 'energy drink' ameliorates subjective and performance deficits during prolonged cognitive demand. Appetite, 42, 331-333.

Seidl, R., Peyrl, A., Nicham, R., \& Hauser, E. (2000). A taurine and caffeine-containing drink stimulates cognitive performance and well-being. Amino Acids, 19, 635-642.

Smit, H. J., Cotton, J. R., Hughes, S. C. \& Rogers, P. J. (2004). Mood and cognitive performance effects of "energy" drink constituents: caffeine, glucose and carbonation. Nutritional Neuroscience, 7. Retreived August 16, 2010 from http://www.biomedsearch.com/nih/Mood-cognitiveperformance-effects-energy/15526987.html

Smit, H. J., \& Rogers, P. J. (2002). Effects of 'energy' drinks on mood and mental performance: Critical methodology. Food Quality and Preference, 13, 317-326.

The Top 15 Energy Drink Brands. (2008, April). Retrieved May 21, 2010, from http://www.energyfiend.com/2007/04/the-15-top-energy-drink-brands

Warburton, D. M., Bersellini, E., Sweeney, E. (2001). An evaluation of a caffeinated taurine drink on mood, memory and information processing in healthy volunteers without caffeine abstinence. Psychopharmacology, 158, 322-328. 
Woolsey, C. (2007). A study of NCAA division I athletes on the use and effects of combining alcohol \& energy drinks. Doctoral dissertation, University of Missouri, Columbia. Retrieved December 10, 2009, from http://edt.missouri.edu/Summer2007/Dissertation/WoolseyC-071207D7933/research.pdf 